\title{
Antimicrobial Activity of Metal Cystine Complexes
}

\section{J ahan Ara Khanam¹, Most. Ferdousi Begum², J esmine Ara ${ }^{3}$, Mele J esmin ${ }^{4}$, M. Abu Taher ${ }^{5}$ and S. M. Mohsin $\mathrm{Ali}^{3}$}

\author{
${ }^{1}$ Department of Biochemistry and Molecular Biology, Rajshahi University, Rajshahi-6205, Bangladesh \\ ${ }^{2}$ Department of Botany, Rajshahi University, Rajshahi-6205, Bangladesh \\ ${ }^{3}$ Department of Applied Chemistry and Chemical Technology, Rajshahi University, Rajshahi-6205, Bangladesh \\ ${ }^{4}$ BCSIR, Rajshahi-6206, Bangladesh
}

\begin{abstract}
Metal cystine complexes of nickel(II), mercury(II) and cadmium(II) have been synthesized and their antimicrobial activities have been evaluated. It is found that mercury(II) cystine and cadmium(II) cystine complexes have pronounced antibacterial and antifungal activities. On the other hand nickel(II) cystine shows moderate activities. The $\mathrm{LC}_{50}$ values of nickel(II) cystine, mercury(II) cystine and cadmium(II) cystine are found to be 5.2, 8.0 and $7.2 \mu \mathrm{g} \mathrm{ml}^{-1}$, respectively. These values were obtained from cytotoxic studies indicating that they are biologically active compounds.
\end{abstract}

Key words: Antimicrobial activity, Cytotoxic activity; Metal amino acid complexes.

\section{INTRODUCTION}

Constituents from natural resources ${ }^{1-4}$ as well as synthetic $^{5,6}$ organic and inorganic compounds have been receiving increasing attention in biological systems. Many of these compounds are being used as chemotherapeutic agents against infectious diseases. As a matter of fact no such agents till now can able to destroy effectively pathogenic micro organism. It is mainly because these pathogenic organisms are developing resistance heriditically towards these agents. It is therefore, necessary to find out consistently new, more safe, effective and inexpensive agents for the purpose. In this connection, a few metal coordination complexes have already been appeared in the literature ${ }^{7,8}$ as antibacterial agents. Treshchalina et al. ${ }^{9}$ studied antitumour properties of some amino acid complexes

Correspondence to: Jahan Ara Khanam

Dhaka Univ. J. Pharm. Sci. 5(1-2): 29-32, 2006 (June-December) of copper(II). The above informations inspired us to study the anti-microbial activity of cystine complexes of some divalent metals namely nickel(II), cadmium(II) and mercury(II). In addition cytotoxic effects of these complexes have also been studied.

\section{MATERIALS AND METHODS}

Synthesis and characterization of the complexes. All metal complexes were prepared ${ }^{10}$ by the direct combination of saturated aqueous solutions of metal acetates with that of L(-) cystine in metal/legand ratio of $1: 1$. The mixture solution was heated to about $60^{\circ} \mathrm{C}$ on water bath to reduce half of its volume. It took about 6-8 hours. The purity of these compounds was confirmed by measuring density and also taking melting points and IR spectral data.

Brine shrimp bioassay method. ${ }^{11}$ For this study, we have used artificial seawater, which was prepared by dissolving $38 \mathrm{~g}$ of sodium chloride in $1 \mathrm{~L}-$ distilled water. Shrimp livers were added to it. The 
temperature was maintained at $37^{\circ} \mathrm{C}$ with a thermostatic system having a light source. The medium was provided with constant oxygen supply. Two days were allowed for the shrimp to hatch and mature as nauplii.

Stock solution. Metal cystine solution was prepared by dissolving $75 \mathrm{mg}$ solid in $25 \mathrm{~mL}$ water.

Methodology. Seven clean vials were taken for the experiment ( 6 for different concentrations and one for the control). Exactly $5 \mathrm{ml}$ seawater was given to each of the vials. Stock solution was then added to the vials with the aid of a micro pipette so as to get final concentrations of $3 \mu \mathrm{g} \mathrm{ml}^{-1}, 6 \mu \mathrm{g} \mathrm{ml}^{-1}, 9 \mu \mathrm{g} \mathrm{ml}^{-1}$, $12 \mu \mathrm{g} \mathrm{ml} l^{-1}, 15 \mu \mathrm{g} \mathrm{ml}^{-1}$ and $18 \mu \mathrm{g} \mathrm{ml}^{-1}$. No sample solution was added to that of the control. With the help of a pasteur pipette 10 living shrimps were taken to each of these seven vials. After 24 hours, the survived nauplii in each vials were counted and the results were noted.

Screening method. The antimicrobial screening was performed by disc diffusion method as described elsewhere. ${ }^{12,13}$

Test organisms for antibacterial activity. The following bacteria were used for the study.

1. Bacillus subtilis

2. Salmonella typhi

3. Shigella dysenteriae

4. Shigella flexneriae

5. Staphylococcus aureus

6. Streptococcus- $\beta$ - haemolyticus

Procedure. Solutions of known concentration of the test samples were made by dissolving in distilled water. Dried and sterilized filler paper discs $(5 \mathrm{~mm}$ in diameter) soaked with known amount of test agents were placed on the nutrient agent media solidified in petridishes $(120 \mathrm{~mm}$ diameter) and inoculated with the test organisms. These plates were than kept at low temperature $\left(4^{\circ} \mathrm{C}\right)$ for 24 hours to allow maximum diffusion and then in an incubator at $37^{\circ} \mathrm{C}$ for 24 hours to allow maximum growth of the organisms. The antibacterial activity was determined by measuring the diameter of zone of inhibition in $\mathrm{mm}$.
Antifungal screening. The antifungal screening was also performed by disc diffusion method. ${ }^{12,13}$ The following fungi were selected for this study.

1. Aspergillus niger

2. Aspergillus flavus

3. Aspergillus fuserium

4. Aspergillus fumigatus

5. Tricodarma harzianum

6. Candida albicans

7. Penicillium sp.

Methodology. The test samples were dissolved in distilled water to make $24 \mu \mathrm{g} / \mathrm{ml}$ and $12 \mu \mathrm{g} / \mathrm{ml}$ solutions. A solution of $12 \mu \mathrm{g} / \mathrm{ml}$ of standard drug Flugal was also prepared.

Sample discs. Sterilized metrical filter paper discs of $3 \mathrm{~mm}$ diameter were taken in a blank petridish. Sample solution $25 \mu \mathrm{l} /$ discs was applied on the discs with the help of a micropipette in an aseptic condition. The discs were left for a few minutes in the aseptic condition for complete removal of the solvent.

Preparation of inoculums. Isolated spore (4-6 similar) of pure fungus was inoculated in screw capped tube containing equal amount of potato dextrose agar (PDA) media and incubated at $28^{\circ} \mathrm{C}$ for 5-7 days for development of new pure culture that was used as inoculum.

Determination. PDA medium was steamed to dissolve and dispersed $4 \mathrm{ml}$ amount of it in to a petridish. It was then autoclaved at $121^{\circ} \mathrm{C}$ for 15 minutes. It was allowed to cool to $30^{\circ} \mathrm{C}$ until the media became solid.

Each petridish was inoculated with different types of inoculums removed from a seven days old culture of fungi. Dried and sterile sample discs and standard (Flugal) disc were placed on nutrient agar plates seeded with the test organism. These were then kept at low temperature $\left(4^{\circ} \mathrm{C}\right)$ for 24 hours to allow maximum diffusion. Finally the petridishes were inoculated at $27-28^{\circ} \mathrm{C}$ for 5-7 days. The activity was justified by measuring the diameter of zone of inhibition in $\mathrm{mm}$. 


\section{RESULTS AND DISCUSSION}

All these complexes showed positive results in brine shrimp lethality bioassay. For determination of cytotoxic effect, medium lethal concentration $\left(\mathrm{LC}_{50}\right)$ of brine shrimp lethality was measured from the plots of percentage of mortality versus concentration of the test samples (Figure 1). The data thus obtained have been presented in Table 1. The mortality rate of the brine shrimp is found to be increased with the increase of concentration of the samples. So there is a positive correlation between brine shrimp toxicity and cytotoxicity. The very low values of $\mathrm{LC}_{50}$ indicate the high cytotoxic effect of all these complexes.

The antibacterial activity of $\operatorname{Hg}(\mathrm{II})$ cystine, $\mathrm{Cd}(\mathrm{II})$ cystine and $\mathrm{Ni}$ (II) cystine measured interms of zone of inhibition has been shown in Table 2. The complexes showed a remarkable sensitivity against a number of both gram-positive and gram-negative bacteria. The results obtained with the standard drug Kanamycin have also been presented here for comparison purpose.

Table 1. Physical parameters of the complexes.

\begin{tabular}{lcccc}
\hline Test compounds & $\mathrm{LC}_{50}, \mathrm{Mgml}^{-1}$ & Melting point, ${ }^{\circ} \mathrm{C}$ & Density,g/cc & Half life, hour \\
\hline $\mathrm{Ni}(\mathrm{II})$ cystine & 5.2 & 300 & 2.51 & 90 \\
$\mathrm{Hg}(\mathrm{II})$ cystine & 8.0 & 180 & 3.56 & 60 \\
$\mathrm{Cd}(\mathrm{II})$ cystine & 7.2 & 80 & 3.25 & 110 \\
\hline
\end{tabular}

Table 2. Data of antibacterial activity of the complexes.

\begin{tabular}{|c|c|c|c|c|c|c|c|}
\hline \multirow{3}{*}{ Test bacteria } & \multicolumn{7}{|c|}{ Diameter of zone of inhibition, $\mathrm{mm}$. } \\
\hline & \multicolumn{2}{|c|}{$\mathrm{Hg}(\mathrm{II})$ cystine, $\mu \mathrm{g} / \mathrm{disc}$} & \multicolumn{2}{|c|}{$\mathrm{Cd}(\mathrm{II})$ cystine, $\mu \mathrm{g} / \mathrm{disc}$} & \multicolumn{2}{|c|}{$\mathrm{Ni}(\mathrm{II})$ cystine, $\mu \mathrm{g} / \mathrm{disc}$} & \multirow{2}{*}{$\frac{\text { Kanamycin, } \mu \mathrm{g} / \mathrm{disc}}{30}$} \\
\hline & 50 & 80 & 50 & 80 & 100 & 200 & \\
\hline Staphytococus aureus & 17 & 28 & 22 & 35 & 11 & 17 & 19 \\
\hline Bacillus subtilis & 18 & 31 & 28 & 39 & 12 & 15 & 24 \\
\hline Shigella dysonteriae & 23 & 34 & 25 & 34 & 10 & 19 & 23 \\
\hline Salmonella typhi & 21 & 32 & 24 & 36 & 5 & 11 & 17 \\
\hline Shigella flexneriae & 25 & 31 & 21 & 28 & 15 & 20 & 25 \\
\hline $\begin{array}{l}\text { Streptococcus - } \beta \text { - } \\
\text { haemolyticus }\end{array}$ & - & - & - & - & 7 & 12 & 21 \\
\hline
\end{tabular}

(-) Expt. was not performed..

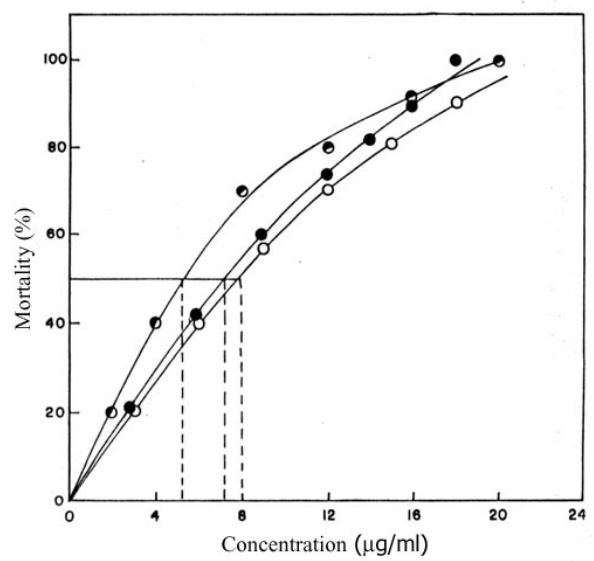

Figure 1. Effect of metal cystine complexes on brine shrimp lethality bioassay. $\mathrm{O}-\mathrm{Hg}(\mathrm{II})$ cystine; $\bullet$-Cd(II) cystine and $\ominus-\mathrm{Ni}(\mathrm{II})$ cystine.
The diameter of zone of inhibition of $\mathrm{Hg}$ (II) cystine complex at the dose of $50 \mu \mathrm{g} /$ disc against Staphylococcus aureus, Bacillus subtilis, Shigella dysenteriae, Salmonella typhi and Shigella flexneriae were found to be 17, 18, 23, 21 and $25 \mathrm{~mm}$, respectively. These values were quite comparable with those obtained with Kanamycin at dose 30 $\mu \mathrm{g} / \mathrm{disc}$ (Table 2). However $\mathrm{Hg}(\mathrm{II})$ cystine complex at dose $80 \mu \mathrm{g} / \mathrm{disc}$ was found to be more sensitive as the zone of inhibition were 28, 31, 34, 32 and $31 \mathrm{~mm}$, respectively for the bacteria stated before. Still better results were obtained with $\mathrm{Cd}(\mathrm{II})$ cystine complexes. However, Ni(II) cystine complex was found to be some what less sensitive. Moderate results were 
obtained when tested with higher doses $(200 \mu \mathrm{g} / \mathrm{disc})$ of the complex.

The antifungal activity of these complexes take the antibacterial activity was measured interms of zone of inhibition against a number of fungi. The results have been presented in table 3 . The results obtained with the standard antifungal agent Flugal have also been shown here (Table 3). Both $\mathrm{Hg}$ (II) cystine and $\mathrm{Cd}(\mathrm{II})$ cystine complexes showed pronounced antifungal activity and even much better than that of Flugal. The zone of inhibition in $\mathrm{mm}$ for Cd(II) cystine with dose $300 \mu \mathrm{g} /$ disc were 33, 28, 22 and 8 for Aspergillus niger. Aspergillus flavus, Aspergillus fuserium and Tricodarma harzianum, respectively. The activity of $\mathrm{Hg}(\mathrm{II})$ cystine with the same dose were 20, 22, 21, 14 and 32 for Asperigullus niger, Aspergillus flavus Aspergillus fumigatus, Tricodarma harzianum and Candida albicans respectively. Moderate activity was found with $\mathrm{Ni(II)}$ cystine complex. It did not show any activity with the fungus Tricodarma harzianum at all.

From the above discussion it can be concluded that at least $\mathrm{Hg}$ (II) cystine and $\mathrm{Cd}(\mathrm{II})$ cystine possess fairly both antibacterial and antifungal activities. Again the positive response in bioassay study suggests that all these complexes might have antitumour activities also. However further studies in advanced level are required to explore these complexes as anticancer agents.

Table 3. Data for antifungal activity of the test compounds.

\begin{tabular}{|c|c|c|c|c|c|c|c|}
\hline \multirow[t]{3}{*}{ Test fungi } & \multicolumn{7}{|c|}{ Diameter of zone of inhibition, mm. } \\
\hline & \multicolumn{2}{|c|}{$\mathrm{Hg}(\mathrm{II})$ cystine, $\mu \mathrm{g} / \mathrm{disc}$} & \multicolumn{2}{|c|}{$\mathrm{Cd}(\mathrm{II})$ cystine, $\mu \mathrm{g} / \mathrm{disc}$} & \multicolumn{2}{|c|}{$\mathrm{Ni}(\mathrm{II})$ cystine, $\mu \mathrm{g} / \mathrm{disc}$} & \multirow{2}{*}{$\frac{\text { Flugal, } \mu \mathrm{g} / \mathrm{disc}}{300}$} \\
\hline & 300 & 600 & 300 & 600 & 300 & 600 & \\
\hline Aspergillus niger & 20 & 27 & 33 & 39 & 6 & 10 & 9 \\
\hline Aspergillus flavus & 22 & 29 & 28 & 34 & 0 & 9 & 12 \\
\hline Aspergillus fuserium & - & - & 22 & 27 & 11 & 24 & 16 \\
\hline Aspergillus fumigatus & 21 & 30 & - & - & - & - & 0 \\
\hline Tricodarma harzianum & 14 & 21 & 8 & 12 & 0 & 0 & 26 \\
\hline Candida albicans & 32 & 37 & - & - & 0 & 11 & 8 \\
\hline Penicillium sp. & - & - & - & - & 11 & 18 & 0 \\
\hline
\end{tabular}

(-) Expt. was not performed; 0-No antifungal activity was found.

\section{REFERENCES}

1. Chowdhury, A.A. and Islam, M.S. 2004. Antimicrobial activity of Trema orientals. Dhaka Univ. J. Pharm. Sci. 3, 53-55.

2. Alam, S., Islam, M.R., Sarkar, M.A., Alam, M.S., Han, K.D., Shim, J.O., Lee, T.S. and Lee, M.W. 2004, In vivo inhibition effect of plant extracts, urine, fertilizers and fungicides on stem rot pathogen of Selerotium. Mycobiology 32, 128-133.

3. Parvez, M.A.K, Khan, M. M. H., Islam, M.Z and Hasan, S. M. 2005, Antimicrobial activities of the petroleum ether methanol and acetone extracts of Kaempferia galamga L Rhizome. J. Life Earth Science 1, 25-29.

4. Parihar, P., Parihar, L. and Bohra, A. 2006, Antibacterial activity of extracts of Pinus roxburghii Sarg. Bangladesh J. Bot. 35, 85-86.

5. Daula, M.A.U., Khanam, J.A. and Masud, Rana A.Y.K.M. 2004, Antibacterial and antifungal activity of 2-oxobenzylidine(3-0x0-aniline) $\mathrm{Cu}(\mathrm{II})$ ethylidinediamine. J. Med. Sci. 4, 124-127.

6. Kamalakannan P and Venkappayya D. 2002. Synthesis and characterization of cobalt and nickel chelates of 5-dimethyl amino methyl 2 thiouracil and their evaluation as antimicrobial and anticancer agents. J. Inorg. Biochem. 21, 22-37.
7. Sultana, C., Rahman, M.A.A., Al. Bari, M.A.A., Banu, M.L. A., Islam, M.S., Khatune, N.A. and Sadik, G. 2003. In vitro antimicrobial screening of three cadmium complexes and two additional compounds of antimoni and arsenic. Pak. J. Bio. Sci. 6, 525-527.

8. Islam, M.S., Farooque, M.A. Bodruddoza, M.A.K., Mosaddik, M.A. and Alam, M.S. 2002. Antimicrobial and toxicological studies of mixed ligand transition metal complexes of schiff bases. Online J. Bio. Sci. 2, 797-799.

9. Treshchaeina, E.M., Konovalova, A.L., Presnov, M.A., Chapurina, L.F. and Belichuk, N.I. 1979. Antitumour properties of mixed coordination compounds of copper(II) and $\alpha$-amino acids. Dokl. Akad. Nauk. 248, 1273-1276.

10. Chakraborty, H. 1993. Ph.D. Thesis, Department of Chemistry, Rajshahi University.

11. Meyer, B.N., Ferringin, N.R., Puans, J.E., Lacobsen, L.B., Nicholas, O.E. and Maclaughlin, J.L. 1982. Brine Shrimp, A convenient general bioassay for active constituents. Planta medica 45, 31-32.

12. Bauer, A.W, Kirby, W.M.M. and Thuruck, M. 1966. Antibiotic susceptibility testing by standardized single disc method. Am. J. Clin, Pathol. 44, 493-496.

13. Rois, J.J., Reico, M.C. and Villar, A. 1988. Antimicrobial screening of natural products. J. Entho. Pharmacol. 23, 127149. 